Corresponding Author: Maria John Spanoudaki; email: maryspan1@gmail.com

Received 20 May 2021

Accepted 14 June 2021

Published 14 January 2022

Production and Hosting by Knowledge E

(c) Maria John Spanoudaki et al. This article is distributed under the terms of the

Creative Commons

Attribution License, which

permits unrestricted use and redistribution provided that the original author and source are credited.

Editor-in-Chief:

Dr. Dimitrios Papandreou

Official Publication of Zayed University, UAE

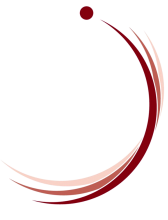

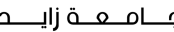
ZAYED UNIVERSITY
Original Article

\section{Association of PC Use and TV Viewing Hours with Women's Recreational Physical Activity and Its Impact on Their Obesity Indices}

\author{
Maria John Spanoudaki ${ }^{1^{*}}$, Antonios Theodoros Cheimaras ${ }^{2}$, Maria Pavlos \\ Papadopoulou², Prokopios Dimitrios Rountos ${ }^{3}$ \\ ${ }^{1}$ Clinical Nutrition and Dietetics Department, 424 General Military Hospital of Thessaloniki, \\ Greece \\ ${ }^{2}$ International Hellenic University, Thermi, Greece \\ ${ }^{3}$ Hellenic Open University, Patra, Greece
}

\section{ORCID}

Maria Pavlos Papadopoulou: https://orcid.org/0000-0002-7925-3267

\section{Abstract}

Background: Television (TV) viewing and computer (PC) use have been associated with poor health outcomes.

Aim: To investigate the association of TV viewing and PC use with recreational physical activity energy expenditure (RPAEE), obesity indices, physical activity levels (PAL) and body fat percentage $(\mathrm{BF} \%)$ of adult women.

Methods: Bodyweight (BW), height, waist (WC) and hip ( $\mathrm{HC}$ ) circumferences of 150 adult women were measured. Body mass index (BMI) and waist-to-hip ratio (WHR) were calculated. The BF\% was measured by bioelectrical impedance analysis. The Athens Physical Activity Questionnaire was used to assess PAL, RPAE, TV viewing and PC hours.

Results: The majority of women (53\%) were overweight and obese, watched TV for $>14 \mathrm{hr} / \mathrm{wk}$ (59\%), and almost half (47\%) of them used computers for $>1 \mathrm{hr} /$ day. Slightly more than half of them (54\%) had a sedentary lifestyle and reported exercise participation for $<2$ hr/wk. No walking for leisure was reported by one-third of the subjects, while an alarming low percentage (0.7\%) walked only $2.5 \mathrm{hr} / \mathrm{wk}$. No participation in informal physical activity was reported by $69 \%$. RPAEE was estimated at $982 \pm 973 \mathrm{kcal} / \mathrm{wk}$ and negatively correlated to TV-watching hours $(r$ $=-0.31, p<0.05)$, computer use $(r=-0.3, p<0.05)$, BMI $(r=-0.44, p<0.01)$, BW $(r=-0.44$, $p<0.01)$, WC ( $r=-0.41, p<0.01)$, WHR ( $r=-0.31, p=0.01)$. Moreover, RPAEE and BF\% were negatively correlated $(r=-0.44, p<0.01)$. BF\% was associated with long hours of $\mathrm{PC}$ use and TV watching $\left(R^{2}=0.11, F_{1.148}=17.94, p=0.00 ; R^{2}=0.14, F_{1.148}=5.4, p=0.002\right)$.

Conclusion: Screen use affecting obesity indices seemed to overrun recreational time for physical activity participation and dominate women's lifestyle. Further research targeting behavioral change practices is recommended.

Keywords: obesity, women, physical activity, recreational physical activity expenditure 


\section{Introduction}

Studies have shown that physical inactivity is strongly associated with poor health outcomes. Leisure-time physical activity seems to decline by age and sedentary behavior has seemingly increased in the European Union [1]. Furthermore, sex is claimed to affect these figures as women are reportedly more inactive than men and more vulnerable to becoming overweight and obese [2, 3].

Obesity is a major health problem affecting men and especially women aged 15-49 years [4-6]. Studies have shown that variable lifestyle factors such as computer (PC) use, television (TV) viewing and physical inactivity are causally related to obesity risk factors including BMI, body fat percentage (BF\%), waist circumference (WC), and waistญto囚hip ratio (WHR), $[7,8,9]$.

Sedentary behavior may be a critical determinant of health, independent of physical activity $[10,11]$. Sedentary lifestyle and physical inactivity are common practices worldwide and are associated with a wide range of chronic diseases and premature death [12, 13]. Although inactivity is known to be harmful, almost one-third of the world's population remains inactive, posing a great risk for public health [14].

The rapid expansion in the use of screen devices contributes to adopting sedentary behavior which leads to the unproductive use of leisure time [15]. Especially, TV viewing adds to the sedentary life of women as they do not participate in exercise on a daily basis, thereby increasing their sitting hours and devoting little time to recreational physical activities. This has an impact on obesity indices and increases the risk of noncommunicable diseases such as obesity, metabolic syndrome, diabetes and cardiovascular disease $[5,14]$. Additionally, it has been shown to affect eating habits by rising consumption of food with high glycemic index and fat content. Therefore, the daily calorie intake is increased while energy expenditure is decreased, which is more likely to develop health issues in the future $[16,17]$.

On the other hand, physical activity and exercise are associated with multiple physical and mental health benefits $[18,19]$, playing a vital role in weight management and improving the level of fasting blood glucose and lipid profile [8]. Consequently, factors which influence women's daily lives are related to eating habits, TV viewing, playing video games and physical activities levels (PAL) [20].

The aim of this study was to investigate the association of PC use and TV-watching time with recreational physical activity energy expenditure (RPAEE), obesity indices, PAL and the effect of screen viewing time on BF\% of adult women. 


\section{Methods}

\subsection{Participants}

One hundred and fifty randomly chosen female subjects, aged 31 to 60 years voluntarily participated in the study. Women who took part in the study gave their written consent prior to participation, in accordance with the Helsinki Declaration. Approval was given by the Scientific Council of 424 General Military Hospital of Thessaloniki. The exclusion criteria were: women aged $<65$ years, pregnant and lactating, diagnosed with cardiovascular, metabolic, gastrointestinal, mental diseases, active systemic infection, orthopedic-neuromuscular problems and undergoing diet treatment for weight loss, dyslipidemia, hypertension and impaired glucose tolerance.

\subsection{Procedure}

Participants were asked to complete a demographic questionnaire. The Athens Physical Activity Questionnaire (APAQ) was also used to assess the PAL [21]. APAQ is a selfadministered questionnaire that records data on physical activity of the previous seven days. The questionnaire asks for three classifications of physical activities: occupational, activities at home and recreational activities; respondents are asked to report their walking habits pertaining to the different parts of their daily life (during working hours, while commuting to work and walking for leisure). In order to estimate the total energy expenditure, APAQ requires sleeping and sedentary behaviors such as TV viewing and PC use to be recorded. Additionally, APAQ estimates RPAEE weekly (kcal/wk), by recording leisure-time physical activities (such as walking, dancing, sitting or standing in a theatre, bar and exercise participation), and PAL. Further, based on the BMI, participants were classified into three categories (normal weight, overweight, and obese). Prevalence of obesity was estimated by BMI values.

\subsection{Anthropometric assessment}

Weight was measured to the nearest $0.1 \mathrm{~kg}$ using a digital scale and wearing light clothing, while height was measured to the nearest $0.5 \mathrm{~cm}$ using a stadiometer at Franfort Horizontal Plane position without shoes. Body Mass Index (BMI) was calculated by Quetelet equation. WC and hip circumference $(\mathrm{HC})$ were measured with a nonexpanded tape and WHR was calculated. The BF\% was measured by a portable body composition analyzer of single frequency, using bioelectrical impedance method. 
TABLE 1: Descriptive characteristics: Mean \pm standard deviation (SD)

\begin{tabular}{|c|c|c|}
\hline & Mean & SD \\
\hline Age (yr) & 44.3 & 9 \\
\hline $\mathrm{BMI}\left(\mathrm{kg} / \mathrm{m}^{2}\right)$ & 26.5 & 6 \\
\hline WC (cm) & 87.4 & 14 \\
\hline $\mathrm{HC}(\mathrm{cm})$ & 108.1 & 11 \\
\hline WHR & 0.8 & 1 \\
\hline BF (\%) & 34,5 & 8.3 \\
\hline PAL & 1.41 & 0.23 \\
\hline RPAEE (kcal/wk) & 982 & 973 \\
\hline TV watching (hr/day) & 2 & 1.3 \\
\hline $\begin{array}{l}\text { Computer use (PC) } \\
\text { (hr/day) }\end{array}$ & 1.8 & 1.6 \\
\hline
\end{tabular}

\subsection{Statistical analysis}

Data were analyzed using SPSS v.23 for Windows. Descriptive and conductive statistics were applied in investigating the association of TV viewing and PC use with obesity indices and leisure-time physical activity (recorded and estimated as RPAEE).

Continuous variables were presented as means \pm standard deviations and categorical ones as absolute and relative frequencies. Kolmogorov-Smirnov test was used to check the distribution of quantitative variables. The level of statistical significance was set at $p$ $<0.05$. Weekly RPAEE and PSL were calculated by APAQ. In addition, participants were classified into three categories (normal weight, overweight and obese) in accordance with the BMI outcome. Regarding conductive statistics, Pearson correlation and stepwise regression were used to estimate the impact of hours spent on TV viewing and PC use on RPAEE and obesity indices (BMI, WC, waist-to-hip ratio, BF\%).

\section{Results}

Table 1 reports the descriptive characteristics of study participants.

Frequency analysis showed that $58.7 \%$ of the women watched TV for $\geq 2 \mathrm{hr} / \mathrm{day}$ and $47 \%$ of them used PC for $\geq 1$ hr/day (Graphs $1 \& 2$, respectively).

Additionally, 37\% of the participants reported no walking for leisure, $15.33 \%$ walked for $2 \mathrm{hr}$ and only $0.7 \%$ walked for $2.5 \mathrm{hr} / \mathrm{wk}$. An intriguing percentage (69\%) of our sample did not participate in any informal physical activity while only $9.3 \%$ and $8.7 \%$ reported participation in an organized form of physical activity for 2 and $3 \mathrm{hr} / \mathrm{wk}$, respectively. Moreover, $47 \%$ of the women had a normal BMI, 33\% were overweight and 20\% obese. RPAEE was estimated at $982 \pm 973 \mathrm{kcal} / \mathrm{wk}$ and had a significantly negative as well as 


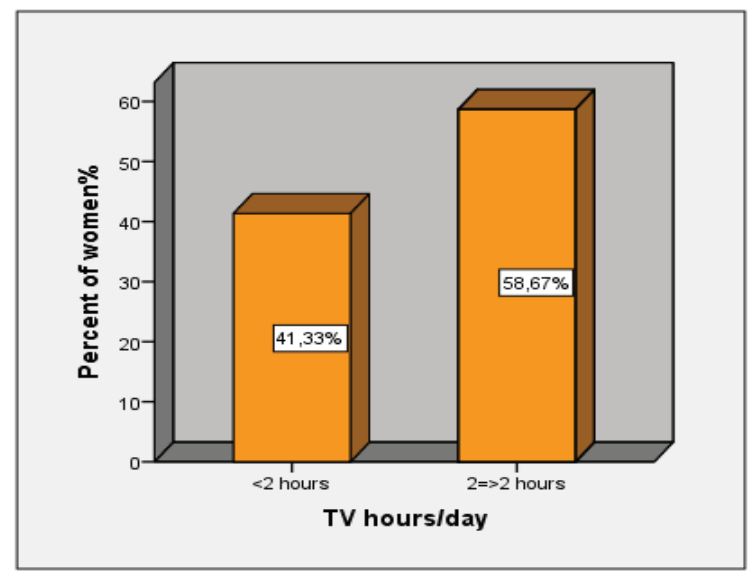

Figure 1: TV viewing (hr/day).

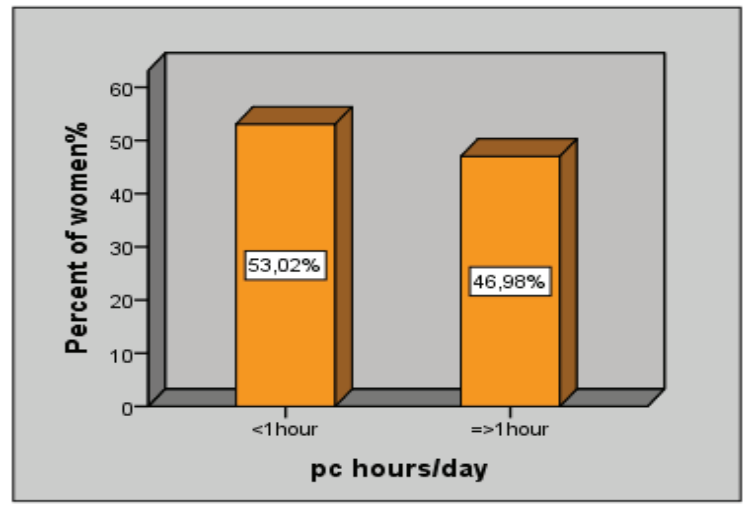

Figure 2: Computer use (hr/day)

weak correlation with TV watching hours $(r=-0.31, N=150, p<0.05)$, PC use $(r=-0.3$, $N=150, p<0.05)$; moderate with BMI $(r=-0.44, N=150, p<0.01)$, bodyweight (BW) $(r=-0.44, N=150, p<0.01)$, WC ( $r=-0.41, N=150, p<0.01)$; and weak with WHR ( $r$ $=-0.31, N=150, p=0.01$ ). There was also a significant moderate negative correlation between RPAEE and BF\% ( $r=-0.44, N=150, p<0.01)$. Age had a significantly negative and weak correlation with PAL and RPAEE $(r=-0.3, N=150, p<0.05 ; r=-0.31, N=$ $150, p<0.01)$.

The effect of TV-viewing and PC-use hours on BF\% (dependent variable) was examined further by stepwise regression analysis which showed that TV viewing hours and PC use were significantly and positively associated with $\mathrm{BF} \%\left(R^{2}=0.11, F_{1.148}=17.94\right.$ and $R^{2}=0.14, F_{1.148}=5.4, p=0.002$, respectively). Particularly, the variable "hours of PC use" was inserted first, which is responsible for $11 \%$ of the variance in the BF\% $\left(R^{2}\right.$ $\left.=0.11, F_{1.148}=17.94, p=0.00\right)$. TV viewing hours were then added and are responsible 
TABLE 2: Correlation of hours of TV viewing and computer use with obesity indices and recreational-time physical activity energy expenditure

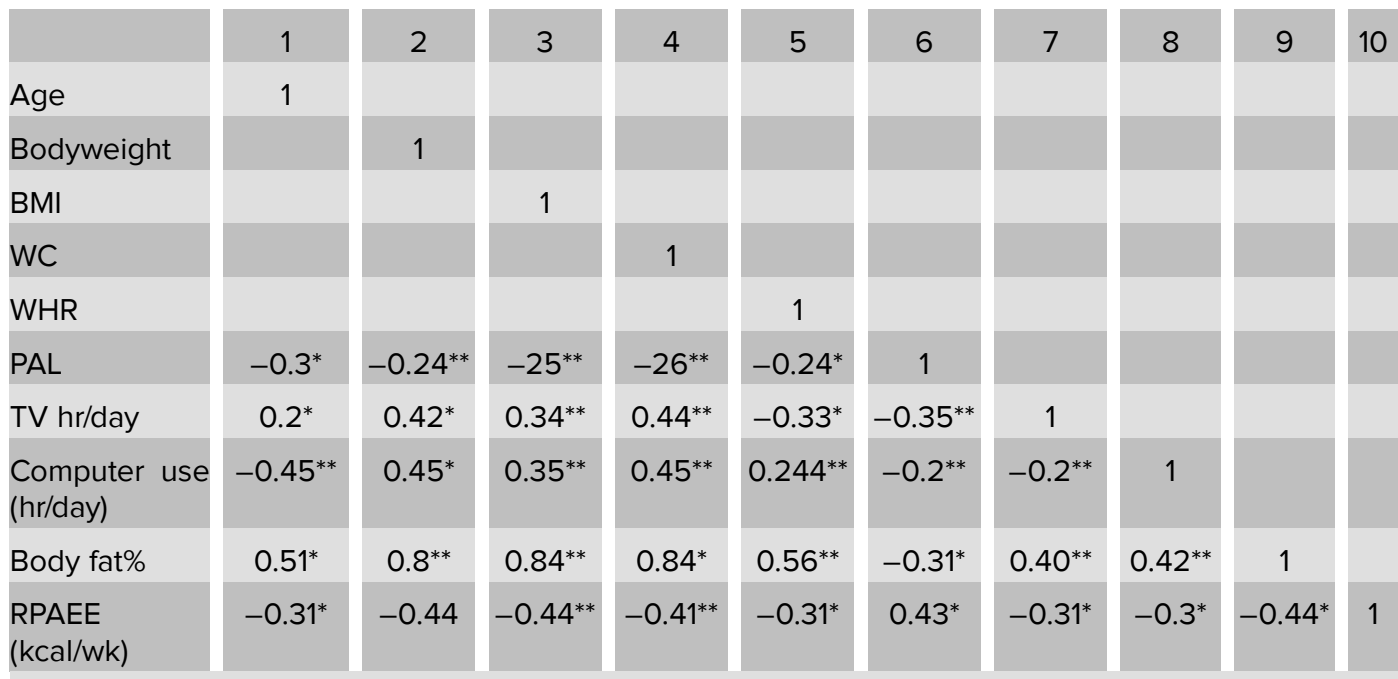

${ }^{* *}$ Correlation is significant at the 0.01 level (2-tailed) * Correlation is significant at the 0.05 level (2-tailed)

TABLE 3: Impact of TV viewing and computer use on body fat percentage

\begin{tabular}{|l|c|c|c|c|c|c|}
\hline Variable & Multiple R & B & $\begin{array}{c}\text { Standard } \\
\text { Error b }\end{array}$ & Beta & t & $\begin{array}{c}\text { Significance } \\
\text { of t }\end{array}$ \\
\hline $\begin{array}{l}\text { Computer } \\
\text { use(hours) }\end{array}$ & 0.33 & 1.3 & 0.35 & 0.33 & 3.7 & 0 \\
\hline TV viewing (hr) & 0.37 & 1.2 & 0.5 & 0.21 & 2.3 & 0.022 \\
\hline
\end{tabular}

for an additional $3 \%$ of the variance $\left(R^{2}=0.14, F_{1.148}=5.4, p=0.02\right)$. Therefore, a higher $\mathrm{BF} \%$ was associated with the higher hours of PC use and of TV watching (Table 3).

\section{Discussion}

Physical inactivity is generally more prevalent among women than men while greater rates have been observed in middle-aged adults [3, 22, 23]. Sedentary and obesogenic behaviors like TV watching and/or PC use are significantly associated with a higher risk of obesity, metabolic syndrome and type-2 diabetes. On the contrary, even light activities like brisk walking have been related to a significantly lower risk of obesity and diabetes $[5,24,25]$.

The aim of this study was to investigate the association of PC use and TV watching time with the RPAEE, obesity indices, the PAL and how screen use affects the BF\% of adult women.

The findings of the present work are consistent with the outcomes of previous investigations. More specifically, 59\% of the adult female participants reported that they watched TV for $\geq 14 \mathrm{hr} / \mathrm{wk}$ and $47 \%$ of them used PC for $\geq 1 \mathrm{hr} / \mathrm{day}$. On the other 
hand, the estimated mean PAL was $1.41 \pm 0.23$. Moreover, $47 \%$ of the women were found to have a normal BMI, $33 \%$ were overweight and $20 \%$ obese. The mean BF\% was $34.5 \%$ for a given mean age of 44 years and $\mathrm{BMI}$ of $26.5 \mathrm{~kg} / \mathrm{m}^{2}$, which is higher than the predicted BF\% for Caucasian women of similar age range and having similar BMI [26, 27]. Hassapidou et al. (2013) reported that $38 \%$ of the adult female population in their study watched TV for $\geq 16 \mathrm{hr} / \mathrm{wk}$, while $90 \%$ of them reported exercise participation for $<2 \mathrm{hr} / \mathrm{wk}$ [28]. Furthermore, the prevalence of obesity in women was $35.5 \%$. Leisure time spent on TV watching and other sedentary behaviors promoted by screen use has been directly associated with obesity indices such as BMI, WC and WHR, lowering metabolic rate due to the decreasing physical activity and increasing calorie intake $[11,23,28,29,30]$. Furthermore, the frequency of watching TV at least once a week was associated with the likelihood of obesity risk independent of the area they lived in compared to ones who did not watch TV [5].

In the second part of our study, we examined the association of PC use and TV watching time with obesity indices. The results showed that TV viewing and PC-use time had a significantly positive correlation with BMI, WC, WHR and BF\%. Additionally, the higher BF\% was associated with the highest hours of PC use and the highest hours of TV watching. The time spent in front of a TV screen has been positively associated with the likelihood of generating metabolic syndrome in adult women irrespective of their PAL [31].

The majority of the participants in our study had a sedentary lifestyle as they reported exercise participation of $<2 \mathrm{hr} / \mathrm{wk}, 37 \%$ of them reported no walking for leisure, $15 \%$ walked for $2 \mathrm{hr}$ and only $0.7 \%$ for $2.5 \mathrm{hr} / \mathrm{wk}$. Almost $70 \%$ of our sample never participated in an organized form of physical activity, while only $9 \%$ reported participation in an organized form of physical activity for 2-3 hr/wk. There was also a significant moderate negative correlation between RPAEE and BF\%, BMI, WC. TV viewing hours and PC use had a negative weak correlation. The mean RPAEE in our study was $980 \mathrm{kcal} / \mathrm{wk}$ while the American College of Sports Medicine recommends a leisure-time physical activity expenditure for maintenance and weight loss as $~ 1200-2000 \mathrm{kcal} / \mathrm{wk}[32,33]$.

\section{Limitations}

The results of the present study cannot be generalized as the sample size was small. We also did not evaluate other factors influencing sedentary lifestyle such us sleeping duration or the socioeconomic status of the participants 


\section{Conclusion}

Participating in any form of physical activity, even walking for leisure, promotes a healthy BW and has mental benefits. On the contrary, sitting time is a structural factor for an obesogenic environment. According to the findings of this study, time spent on TV viewing and PC use was associated with greater BF\%, BMI, WC, WHR and lower PAL. The majority of women in our sample appeared to dedicate many hours to sedentary habits related to screen use, whereas only a few showed interest in increasing their physical activity levels. Using the screen overruns free time for recreational physical activity and results in the rise of sitting time, leading to the reduction of physical activity energy expenditure. Consequently, obesity indices are affected and contribute to an increasing obesity risk. These data, although cannot be generalized, reinforce outcomes of previous studies pointing to the need of further research on motivating the female population to alter environmental factors through the implementation of prevention programs targeting behavioral change practices.

\section{Acknowledgments}

The authors would like to thank Professor Kavouras Stavros for his assistance in conducting the present research.

\section{Funding}

None.

\section{References}

[1] López-Valenciano A, Mayo X, Liguori G, Copeland RJ, Lamb M, Jimenez A. Changes in sedentary behaviour in European Union adults between 2002 and 2017. BMC Public Health. 2020;20(1):1206.

[2] Granger E, Nardo F, Harrison A, Patterson L, Holmes R, Verma A. A systematic review of the relationship of physical activity and health status in adolescents. European Journal of Public Health. 2017;27(2):100-106.

[3] Eduards ES, Sackett SC. Psychosocial variables related to why women are less active than men and related health implications. Clinical Medicine of Omen Health. 2016;9(1):47-56. 
[4] Tauqeer Z, Gomez G, Fatima S. Obesity in women: Insights for the clinician. Journal of Women's Health. 2018;27(4):444-457.

[5] Ghose B. Frequency of TV viewing and prevalence of overweight and obesity among adult women in Bangladesh: a cross-sectional study. BMJ Open. 2016;7(1):1-7.

[6] Roditis ML, Parlapani ES, Tzotzas T, Hassapidou M, Krassas GE. Epidemiology and predisposing factors of obesity in Greece: From the Second World War until today. Journal of Pediatric Endocrinology \& Metabolism. 2009;22(5):389-405.

[7] Kenney E, Gortmaker S. United States adolescents' television, computer, videogame, smartphone, and tablet use: Associations with sugary drinks, sleep, physical activity, and obesity. The Journal of Pediatrics. 2017;182:144-149.

[8] Stoner L, Rowlands D, Morrison A, Credeur D, Hamlin M, Gaffney K, et al. Efficacy of exercise intervention for weight loss in overweight and obese adolescents: Metaanalysis and implications. Sports Medicine. 2016;46(11):1737-1751.

[9] Vandelanotte C, Sugiyama T, Gardiner P, Owen N. Journal of Medical Internet Research. 2009;11(3):1-8.

[10] Houser SH, Joseph R, Puro N, Darrell E. Use of technology in the management of obesity: A literature review. Perspectives in Health Information Management. 2019;16(Fall):1c.

[11] Chaua JY, Grunseita A, Midthjellb K, Holmenb J, Holmenb TL, Baumana AE, et al. Cross-sectional associations of total sitting and leisure screen time with cardiometabolic risk in adults. Results from the HUNT Study Norway. Journal of Science and Medicine in Sport. 2013;17(1):78-84.

[12] Omar ?, Husain ??, Jamil AT, Nor M, Ambak R, Fazliana M, et al. Effect of physical activity on fasting blood glucose and lipid profile among low income housewives in the MyBFF@home study. BMC Women's Health. 2018;18(1):79-98.

[13] Rezende LFM, Lopes MR, Lopez JPR, Matsudo VKR, Luiz OC. Sedentary behavior and health outcomes: An overview of systematic reviews. PLOS One. 2014;9(8):1-7.

[14] Rodulfo J. Sedentary lifestyle a disease from XXI century. Clinica e Investigacion en Arteriosclerosis. 2019;31(5):233-240.

[15] Biddle SJH, García EB, Pedisic Z, Bennie J, Vergeer I, Wiesner G. Screen time, other sedentary behaviours, and obesity risking adults: A review of reviews. Current Obesity Report. 2017;6(2):134-147.

[16] Ofori EK, Angmorterth SK. Relationship between physical activity, body mass index (BMI) and lipid profile of students in Ghana. Pan African Medical Journal. 2019;33(30):1-8. 
[17] Smith L, Fisher A, Hamer M. Television viewing time and risk of incident obesity and central obesity: the English longitudinal study of ageing. BMC Obesity. 2015;2(12):15.

[18] Heidi R, Kyngas H, Tammelin T, Kaariainen M. Systematic review of physical activity and exercise interventions on body mass indices, subsequent physical activity and psychological symptoms in overweight and obese adolescents. Journal of Advanced Nursing. 2015;71(11):2461-2477.

[19] Garber CE, Blissmer B, Deschenes MR, Franklin BA, Lamonte MJ, Lee I-M, et al. Quantity and quality of exercise for developing and maintaining cardiorespiratory, musculoskeletal, and neuromotor fitness in apparently healthy adults: Guidance for prescribing exercise. American College of Sports Medicine. 2011;43(7):1334-1359.

[20] Davison KK, Marshall SJ, Birch LL. Cross-sectional and longitudinal associations between tv viewing and girls' body mass index, overweight status, and percentage of body fat. Journal of Pediatrics. 2006;149(1):1-11.

[21] Kavouras S, Maraki MI, Kollia M, Gioxari A, Jansen LT, Sidossis LS. Development, reliability and validity of a physical activity questionnaire for estimating energy expenditure in Greek adults. Science and Sports. 2016;31(3):e47-e53.

[22] Codina N, Pestana JV. Time matters differently in leisure experience for men and women: leisure dedication and time perspective. International Journal of Environmental Research and Public Health. 2019;16(14):1-11.

[23] Pitsavos C, Panagiotakos DB, Lentzas Y, Skoumas Y, Papadimitriou L, Zeimbekis A, et al. Determinants of physical inactivity among men and women from Greece: A 5-year follow-up of the ATTICA. Study Annals of Epidemiology. 2008;18(5):387-394.

[24] Hu FB, Li TY, Colditz GA, Willet WC, Manson JE. Television watching and other sedentary behaviors in relation to risk of obesity and type 2 diabetes mellitus in women. JAMA. 2003;289(14):1785-1791.

[25] Verghese J, Lipton RB, Katz MJ, Hall CB, Derby CA, Kuslansky G, Ambrose AF, et al. Leisure activities and the risk of dementia in the elderly. The New England Journal of Medicine. 2003;348(25):2508-2516.

[26] Kim YJ, Han SH, Yang BM. Implication of high-body-fat percentage on cardiometabolic risk in middle-aged, healthy, normal-weight adults. Obesity. 2013;21(8):1571-1577.

[27] Gallagher D, Heymsfield SB, Heo M, Jebb S, Murgatroyd PR, Sakamoto Y. Healthy percentage body fat ranges: an approach for developing guidelines based on body mass index 1-3. The American Journal of Clinical Nutrition. 2000;72(3):694-701. 
[28] Hassapidou M, Papadopoulou S, Vlahavas G, Kapantais E, Kaklamanou D, Pagkalos I, et al. Association of physical activity and sedentary lifestyle patterns with obesity and cardiometabolic comorbidities in Greek adults: Data from the National Epidemiological Survey. Hormones. 2013;12(2):265-274.

[29] Williams D, Raynor H, Ciccolo JT. A review of TV viewing and its association with health outcomes in adults. American Journal of Lifestyle Medicine. 2008;3(2):250259.

[30] Yannakoulia M, Karayiannis D, Terzidou M, Kokkevi A, Sidossis LS. Nutrition-related habits of Greek adolescents. European Journal of Clinical Nutrition. 2004;58(4):580_ 586.

[31] Bertrais S, Ondoua JPB, Czernichow S, Galan P, Hercberg S, Oppert JM. Sedentary behaviors, physical activity, and metabolic syndrome in middle-aged French subjects. Obesity Research. 2005;13(5), 936-944.

[32] Jakicic JM, Powell KE, Campbell WW, Dipietro L, Pate RR, Pescatello LS, et al. Physical activity and the prevention of weight gain in adults: A systematic review. Medicine and Science in Sports and Exercise. 2019;51(6):1262-1269.

[33] Donnelly JE, Blair SN, Jakicic JM, Manore M, Rankin JW, Smith B. Appropriate physical activity intervention strategies for weight loss and prevention of weight regain for adults. The American College of Sports Medicine. 2009;41(2):459-471. 